\title{
Papillary thyroid carcinoma presenting as metastases at unexpected sites: Report of two cases
}

\author{
Renu Thomas, Elezabeth Manuel \\ Department of Histopathology, VPS Lakeshore Hospital and Research Centre, Kochi, India
}

Received: May 19, 2020

Accepted: July 6, 2020

Online Published: September 10, 2020

DOI: $10.5430 /$ dcc.v7n2p1

URL: https://doi.org/10.5430/dcc.v7n2p1

\begin{abstract}
Papillary thyroid carcinoma (PTC) is the most common form of differentiated thyroid carcinoma (DTC). It is generally confined to the neck with or without spread to regional lymph nodes. Distant metastases is rare, if occurs, it usually involves lung and bone. Additional locations have only been sporadically reported and were identified during the course of follow-up, subsequently to a thyroid surgery. Distant metastases as the initial presentation of PTC is a rare event. We, herein, report two cases of PTC presenting initially as metastases at unusual sites and discuss the importance of meticulous histopathological and immunohistochemical examination in such situations. Our aim is to increase awareness of the unique possibility of PTC presenting as metastatic deposits at unexpected sites.
\end{abstract}

Key Words: Thyroid carcinoma, Papillary, Metastases

\section{INTRODUCTION}

Papillary and follicular carcinomas of thyroid are the differentiated thyroid carcinoma (DTC), characterized by a slowly progressive course with 10 year survival rates as high as 80\%-95\%. ${ }^{[1]}$ Papillary thyroid carcinoma (PTC) which is the most common thyroid tumour represent $79 \%$ of thyroid malignancies, is generally confined to the neck with or without spread to regional lymph nodes, with 10 year mortality rate less than $7 \% .^{[2]}$ However, $4 \%-8 \%$ of patients develop distant metastasis, most common sites being bone and lung. ${ }^{[3]}$ Presence of distant metastasis is the most significant poor prognostic factor with 10 year survival rate falling to less than 50\%. ${ }^{[4]}$ Herein, we report two rare presentations of PTC as metastases at unusual sites.

\section{CASE REPORT}

\subsection{Case 1}

A 47-year-old male patient presented with one month history of fever to an outside hospital. Ultrasonogram of abdomen done at that centre along with routine laboratory investigations, revealed a large mass lesion over left kidney. Therefore an MRI scan of abdomen was taken, which confirmed a large, $10 \mathrm{~cm}-12 \mathrm{~cm}$ mass lesion arising from left adrenal gland and adhering to left kidney. He was thereafter, referred to our hospital and underwent left adrenalectomy and radical nephrectomy.

Resected specimen was composed of kidney measuring $17 \mathrm{~cm} \times 13 \mathrm{~cm} \times 9 \mathrm{~cm}$ with an adhering encapsulated tumour measuring $12 \mathrm{~cm} \times 8 \mathrm{~cm} \times 7 \mathrm{~cm}$ in the suprarenal region. Cut section of the growth was whitish solid and vaguely

\footnotetext{
*Correspondence: Renu Thomas; Email: resurenu@yahoo.co.uk; Address: Department of Histopathology, VPS Lakeshore Hospital and Research Centre, Kochi-682040, India.
} 
lobulated. Central necrosis and cystic changes were present. Microscopic examination showed an encapsulated malignant epithelial neoplasm composed of rather regular cells forming follicles (see Figure 1A). Individual cells showed vesicular round to oval nuclei with clearing, inconspicuous nucleoli and eosinophilic granular cytoplasm. Several cells showed nuclear grooving. Large areas of necrosis, lymphovascular emboli and frequent mitosis > 10/10 HPF were observed.

The possibilities considered, based on this morphology were a neuroendocrine neoplasm, thyroid like follicular renal cell carcinoma arising from the kidney and metastatic follicular patterned carcinoma of thyroid origin. Immunohistochemical studies (Bond Polymer refine detection method using Leica BOND MAX fully automated IHC machine) were performed which showed tumour cells staining positive for Cytokeratin 7 (Dako), thyroid transcription factor1 (TTF1-Dako) (see Figure 1B), thyroglobulin (PathNsitu) (see Figure 1C) and Pax8 (PathNsitu) (see Figure 1D). Cytokeratin 20 (PathN- situ), neuroendocrine markers - synaptophysin (PathNsitu) and chromogranin (PathNsitu) and inhibin (Biogenex) - a marker for adrenocortical carcinoma were negative. This led to a diagnosis of metastatic thyroid carcinoma with features favouring follicular variant of papillary carcinoma.

Following this, an ultrasound scan of the neck was done which showed multiple nodules in both thyroid lobes with a suspicious nodule in the inferior pole of right lobe, measuring $3 \mathrm{~cm} \times 2 \mathrm{~cm}$ in size. Fine needle aspiration cytology from this nodule confirmed PTC. CT thorax and PET scan did not detect any other metastatic deposits.

Patient underwent total thyroidectomy which revealed multifocal PTC - follicular variant (see Figure 2), involving right and left lobes; tumour size ranging from $0.4 \mathrm{~cm}$ to $4 \mathrm{~cm} \times$ $2.5 \mathrm{~cm} \times 2 \mathrm{~cm}$ in a background of nodular hyperplasia with lymphocytic thyroiditis. Extrathyroidal extension was not present and regional lymphnodes were free of tumour.

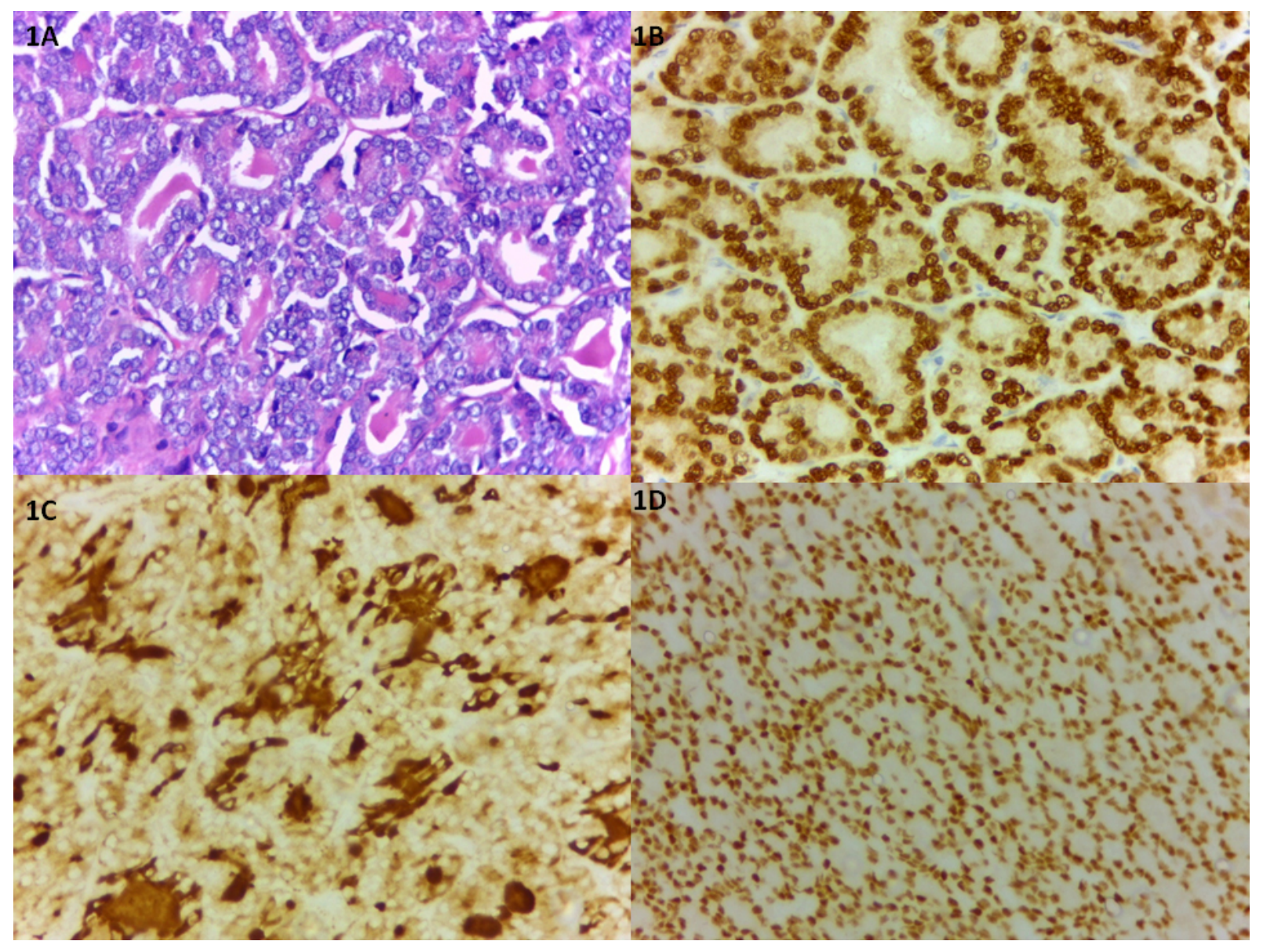

Figure 1. Histopathology of adrenal tumour

A. Tumour showing cells forming follicles, individual cells have clear nuclei with grooving-hematoxylin-eosin, original magnification $\times 400$; B. Immunohistochemical staining with TTF1 showing diffuse nuclear staining-original magnification $\times 400$;

C. Immunohistochemical staining with thyroglobulin showing diffuse cytoplasmic staining-original magnification $\times 200$;

D. Immunohistochemical staining with Pax8 showing diffuse nuclear staining-original magnification $\times 200$. 


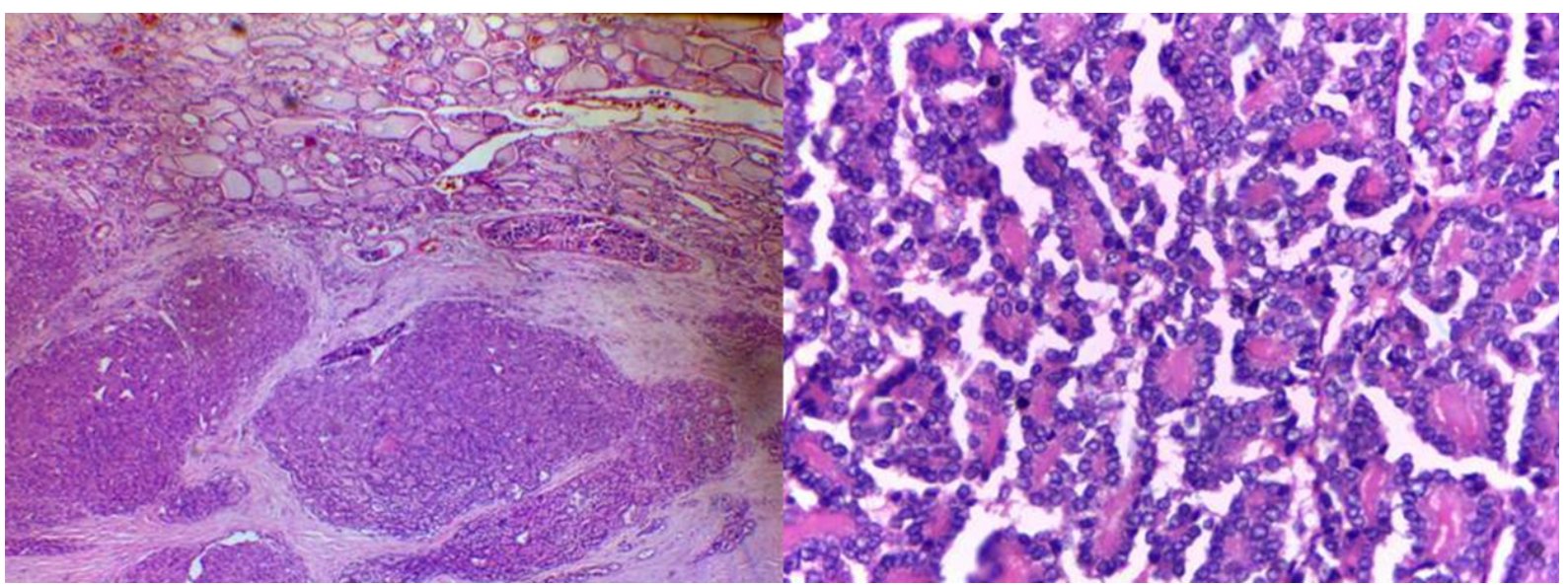

Figure 2. Histopathology of tumour in the thyroid Left: Low power view showing tumour nodules surrounded by normal thyroid tissue, hematoxylin-eosin, original magnification $\times 100$; Right: High power view showing features of papillary carcinoma-follicular variant, similar to the adrenal tumour, hematoxylin-eosin, original magnification $\times 400$.

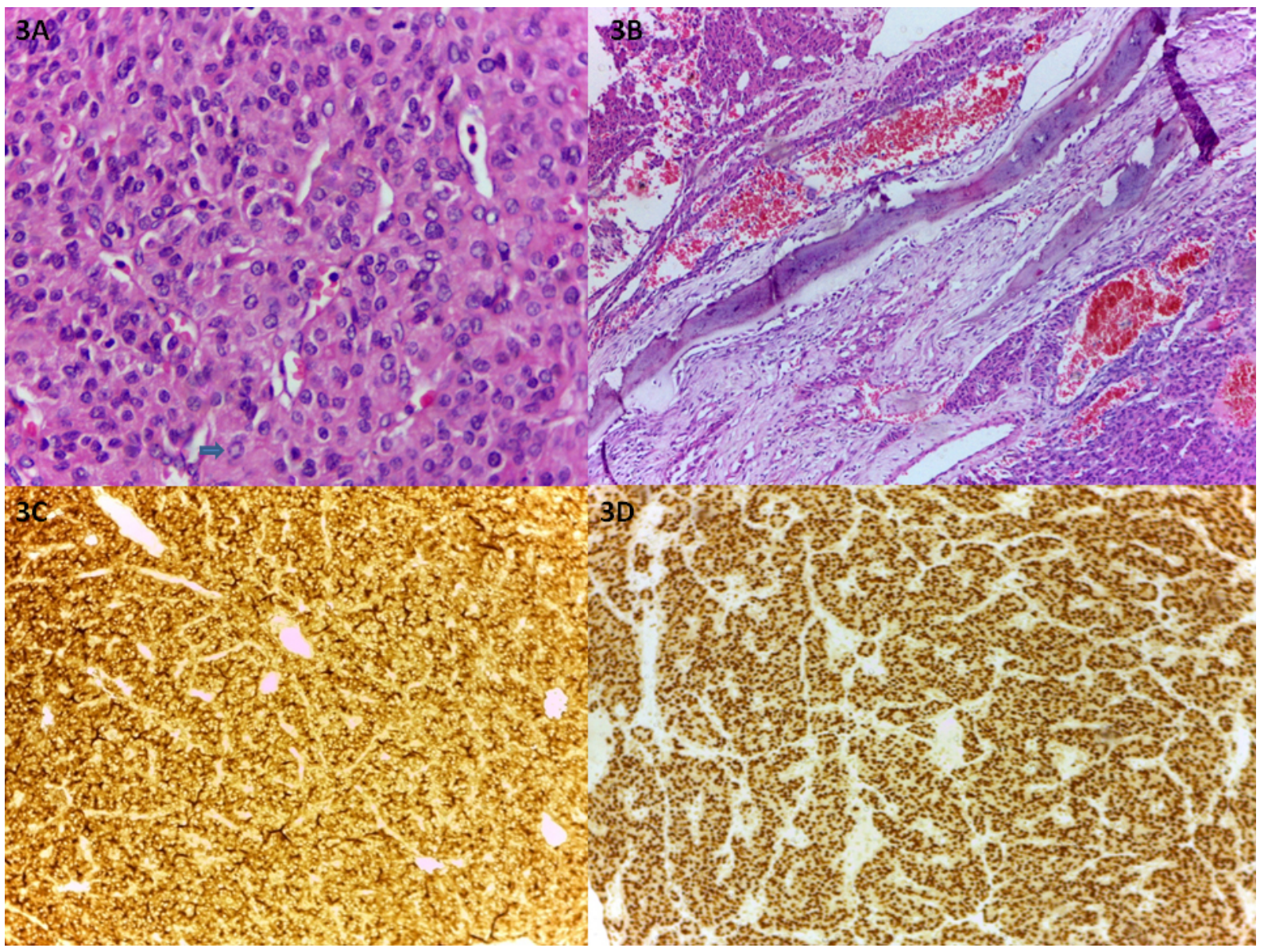

Figure 3. Histopathology of scalp swelling showing papillary thyroid carcinoma

A. Nests of cells showing nuclear clearing, grooving and psudoinclusions(arrow)-hematoxylin-eosin, original magnification $\times 400$; $B$. Tumour eroding through skull bone-hematoxylin-eosin,original magnification $\times 100$; C. Immunohistochemical staining with thyroglobulin showing diffuse cytoplasmic staining-original magnification $\times 200$; D. Immunohistochemical staining with TTF1 showing diffuse nuclear staining-original magnification $\times 200$. 


\subsection{Case 2}

A 54-year-old male patient presented with one month history of scalp swelling, which was not associated with pain. CT and MRI scan showed enhancing dural based mass eroding through the bone and elevating overlying skin, suggestive of meningioma. He underwent excision of the same. Intraoperatively, firm vascular mass, densely adherent to dura, eroding the bone but sparing arachnoid mater was found. Excised specimen consisted of a nodular, fairly circumscribed mass, measuring $3.5 \mathrm{~cm} \times 3.5 \mathrm{~cm} \times 1.5 \mathrm{~cm}$, attached to dura and eroding through attached bone. Cut section had tan, focally haemorrhagic appearance. Microscopic examination showed a cellular neoplasm composed of closely packed cells with round to ovoid vesicular nuclei with clearing and grooving and eosinophilic granular cytoplasm, arranged in nests and trabeculae with intervening thin walled vascular channels (see Figure 3A, B). Frequent mitoses, 8-10/10HPF were observed. These morphological features were suggestive of a malignant neoplasm, differential diagnoses were anaplastic meningioma and metastatic carcinoma.

On immunohistochemical studies (Bond Polymer refine detection method using Leica BOND MAX fully automated IHC machine), tumour cells stained diffusely for pancytokeratin (Zytomed), cytokeratin 7 (Dako), Vimentin (Dako), thyroglobulin (PathNsitu) (see Figure 3C), TTF1 (Dako) (see Figure 3D) and Pax8 (PathNsitu), confirming metastatic carcinoma of thyroid origin. Cytokeratin 20 (PathNsitu), Epithelial membrane antigen (Dako), neuroendocrine markersynaptophysin (PathNsitu), markers for lung carcinomaNapsin (PathNsitu) and P63 (PathNsitu) and marker for GIT tumours CDX2 (PathNsitu) were negative. The patient then underwent ultrasound scan of the neck which showed a $1.6 \mathrm{~cm}$ hypoecogenic nodule in the right thyroid lobe. The patient was not willing for further investigations due to financial constraints and was lost to follow up.

\section{Discussion}

Distant metastases prior to a primary thyroid cancer diagnosis are extremely infrequent but when occurs, pose diagnostic challenges, especially when presenting at unusual sites. Rare distant metastatic locations of PTC that have been sporadically reported include the following: liver, pancreas, spleen, kidney, adrenal gland, brain, cerebellum, skeletal muscle, parotid gland, skin, and so on. ${ }^{[5-14]}$

Less than 1/2,000 thyroid tumours initally manifest as adrenal metastasis ${ }^{[15]}$ and they are usually multiple, bilateral and often associated with lung or bone metastases. ${ }^{[16,17]}$ In our case, metastasis was solitary and unilateral in the left adrenal gland without evidence of involvement of other common locations like lung or bone.
Skull base metastasis from DTC is a rare manifestation with only 28 reported cases, including 18 cases from follicular thyroid carcinoma (FTC) and 10 cases from PTC ${ }^{[18]}$ Diagnosis in the presence of silent primary sites is challenging, because these lesions are often mistaken for primary tumours like meningioma, or schwannoma on CT and magnetic resonance imaging. ${ }^{[19]}$

Histopathology along with immunohistochemical examination is crucial in diagnosing metastasis from DTC. In routine practice, thyroglobulin (TGB) and thyroid transcription factor-1 (TTF1) are the most commonly used immunomarkers to identify thyroid tumors in the setting of metastasis. TGB, a thyroid hormone precursor, is a glycoprotein synthesized by thyrocytes constituting the major component of colloid. The expression of TGB, shows a certain degree of correlation with tumor differentiation and are less sensitive in poorly differentiated tumours. ${ }^{[20-22]}$ TTF- 1 is a more sensitive marker for poorly differentiated carcinomas and metastasis. TTF1 expression is reported in nearly $100 \%$ of PTC and FTC. ${ }^{[20-22]}$ Paired box gene 8 (PAX8), a novel marker, is a member of the paired box (PAX) family of transcription factors and is reported to have a positive rate of nearly $100 \%$ in PTCs and $91 \%$ to $100 \%$ in FTCs. ${ }^{[23]}$ In both our cases, primary thyroid tumour was detected later; so histological features along with combined expression of TTF-1, Thyroglobulin and PAX8 were crucial in arriving at the correct diagnosis. In the first case, thyroid like follicular renal cell carcinoma which is an emerging entity with morphological resemblance to a primary thyroid neoplasm was a close differential diagnosis but they do not stain with TTF1 or TG and therefore was excluded. The clinical, radiological and peroperative diagnosis in the second case was meningioma. Hence, in both cases immunohistochemical studies were pivotal in arriving at the correct diagnosis.

The follicular variant of papillary thyroid carcinoma (FVPTC) is a major subtype of PTC. Patients with FVPTC and patients with classical PTC show similar clinical characteristics and prognostic factors. ${ }^{[24]}$ However, there have been a few reports of "aggressive" FVPTC that have metastasized hematogenously; these neoplasms have been diffusely invasive or multicentric in the thyroid and clinically behave as hybrids between follicular carcinoma and PTC. ${ }^{[25]}$ According to published meta-analyses of PTC, TERT promoter and BRAFV600E mutations were associated with aggressive clinicopathological features. ${ }^{[26,27]}$

The incidence of DTC has rapidly increased worldwide over the last decades, largely attributable to increased detection and not due to a true population level increase in tumorigenesis. Several studies assessing the incidence of DTC and thy- 
roidectomies over long periods found doubling of both while DTC specific mortality rate remains unchanged; therefore suggesting watchful waiting as a safe route for management of these cases, especially the early stage and papillary subtype, to reduce the economic burden of potentially avoidable thyroidectomies. ${ }^{[28,29]}$ The two cases illustrated here raise concerns to such an approach. Distant metastases in DTC represents advanced disease stage and are often associated with poor prognosis. Therefore, earlier detection of clinically silent primary tumours has a significant impact on prognosis of these patients and clinical decision-making. Incorporation of molecular diagnostics may evolve as a promising tool in risk stratification in these cases.

To date, the best therapeutic option for PTC with distant metastases is resection of metastatic tumour along with to- tal thyroidectomy, followed by radioacive iodine ablation therapy. ${ }^{[30]}$

\section{Conclusion}

Our cases are rare presentations of PTC as a solitary metastatic lesion at unusual sites without involvement of commonly affected organs like lung or bone. These cases highlight the importance of early detection of thyroid carcinoma before the development of metastases. Meticulous histopathological and immunohistochemical examination are crucial to arrive at the correct diagnosis while encountering rare tumours.

\section{CONFLicts OF INTEREST Disclosure}

The authors declare they have no conflicts of interest.

\section{REFERENCES}

[1] Cabanillas ME, McFadden DG, Durante C. Thyroid cancer. Lancet. 2016; 388: 2783-95. https://doi.org/10.1016/S0140-673 6(16) $30172-6$

[2] Ito Y, Miyauchi A, Kihara M, et al. Overall survival of papillary thyroid carcinoma patients: a single-institution long-term follow-up of 5897 patients. World J Surg. 2018; 42: 615-22. PMid:29349484. https://doi.org/10.1007/s00268-018-4479-z

[3] Shaha AR, Shah JP, Loree TR. Differentiated thyroid cancer presenting initially with distant metastasis. Am J Surg. 1997; 174: 474-476. https://doi.org/10.1016/S0002-9610(97)00158-X

[4] Elisei R, Molinaro E, Agate L, et al. Are the clinical and pathological features of differentiated thyroid carcinoma really changed over the last 35 years? Study on 4187 patients from a single Italian institution to answer this question, Journal of Clinical Endocrinology and Metabolism. 2010; 95: 1516-1527. PMid:20156922. https://doi.org/10.1210/jc.2009-1536

[5] Djenic B, Duick D, Newell JO, et al. Solitary liver metastasis from follicular variant papillary thyroid carcinoma: a case report and literature review. Int J Surg Case Rep. 2015; 6C: 146-9. PMid:25536153. https://doi.org/10.1016/j.ijscr.2014.11.080

[6] Borschitz T, Eichhorn W, Fottner C, et al. Diagnosis and treatment of pancreatic metastases of a papillary thyroid carcinoma. Thyroid. 2010; 20: 93-8. PMid:20025539. https://doi.org/10.1089/th y. 2009.0026

[7] Gao Y, Deng W, Chen Y, et al. Renal metastases as the initial presentation of papillary thyroid carcinoma: a case report and literature review. Mol Clin Oncol. 2017; 6: 821-4. PMid:28588771. https://doi.org/10.3892/mco.2017.1243

[8] BlaŽeković I, Jukić T, Granić R, et al. An unusual case of papillary thyroid carcinoma Iodine-131 avid metastasis to the Adrenal Gland. Acta Clin Croat. 2018; 57: 372-6. PMid:30431733. https : //doi.org/10.20471/acc.2018.57.02.20

[9] Olson AC, Haugen BR, Walter J, et al. SPECT/CT and I131 Therapy of brain metastases from follicular variant papillary thyroid carcinoma (FVPTC). J Clin Endocrinol Metab. 2014; 99: 3511-2. PMid:25057877. https://doi.org/10.1210/jc.2014-1875

Published by Sciedu Press
[10] Al-Dhahri SF, Al-Amro AS, Al-Shakwer W, et al. Cerebellar mass as a primary presentation of papillary thyroid carcinoma: case report and literature review. Head Neck Oncol. 2009; 1: 23. PMid:19558727. https://doi.org/10.1186/1758-3284-1-23

[11] Kini H, Pai RR, Kalpana S. Solitary parotid metastasis from columnar cell carcinoma of the thyroid: a diagnostic dilemma. Diagn Cytopathol. 2003; 28: 72-5. PMid:12561024. https://doi.org/ $10.1002 / \mathrm{dc} .10226$

[12] Soylu S, Arikan AE, Teksoz S, et al. Skin metastasis on the neck: an unusual presentation of recurrence of papillary thyroid carcinoma. Gland Surg. 2017; 6: 594-7. PMid:29142854. https://doi .org/ $10.21037 / g s .2017 .07 .12$

[13] Nimmagadda A, Krishna Mohan VS, Manthri R, et al. Unusual metastases in papillary microcarcinoma of thyroid. Indian J Nucl Med. 2019; 34: 32-4. PMid:30713376. https://doi .org/10.410 3/ijnm.IJNM_127_18

[14] Herbowski L. Skeletal muscle metastases from papillary and follicular thyroid carcinomas: an extensive review of the literature. Oncol Lett. 2018; 15: 7083-9. PMid:29731874. https://doi.org/10.3 892/ol.2018.8216

[15] Girelli M, Casra D, Rubello D, et al. Metastatic thyroid carcinoma of adrenal gland. J endocrinol invest. 1993; 16(2): 139-41. PMid:8463550. https://doi.org/10.1007/BF03347667

[16] Song HJ, Xue YL, Qiu ZL, et al. Uncommon metastases from differentiated thyroid carcinoma. Hell J Nucl Med. 2012; 15(3): 233-240.

[17] Kumar A, Nadig M, Patra V, et al. Adrenal and renal metastases from follicular thyroid carcinoma. Br J Radiol. 2005; 78: 1038-1041. PMid:16249606. https://doi.org/10.1259/bjr/24024066

[18] Akira M, Mineko M, Katsumi H, et al. Clinicopathological and Molecular Histochemical Review of Skull Base Metastasis from Differentiated Thyroid Carcinoma. Acta Histochem Cytochem. 2013; 46(5): 129-136. PMid:24194626. https://doi .org/10.1267/ah c. 13019

[19] Mutahir AT, Mushabbab AA, Khalid H Al-Q, et al. Skull base metastasis from papillary thyroid carcinoma: a report of three cases. Int Med Case Rep J. 2015; 8: 127-131. PMid:26203287. https://doi.org/10.2147/IMCRJ.S82792 
[20] Haiyan L, Fan L. Application of Immunohistochemistry in Thyroid Pathology. Arch Pathol Lab Med. 2015; 139: 67-82. PMid:25549145. https://doi.org/10.5858/arpa.2014-0056-RA

[21] Trueba SS, Auge J, Mattei G, et al. PAX8, TITF1and FOXE1 gene expression patterns during human development: new insights into human thyroid development and thyroid dysgenesis-associated malformations. J Clin Endocrinol Metab. 2005; 90(1): 455-462. PMid:15494458. https://doi.org/10.1210/jc.2004-1358

[22] Bejarano PA, Nikiforov YE, Swenson ES, et al. Thyroid transcription factor-1, thyroglobulin, cytokeratin 7 and cytokeratin 20 in thyroid neoplasms. Appl Immunohistochem Mol Morphol. 2000; 8(3): 189194. PMid:10981870. https : //doi .org/10.1097/00129039-2 00009000-00004

[23] Bishop JA, Sharma R, Westra WH. PAX8 immunostaining of anaplastic thyroid carcinoma: a reliable means of discerning thyroid origin for undifferentiated tumors of the head and neck. Hum Pathol. 2011 42(12): 1873-1877. PMid:21663937. https ://doi .org/10.101 6/j.humpath.2011.02.004

[24] Lin JD, Hsueh C, Huang BY. Papillary thyroid carcinoma with different histological patterns. Chang Gung Medical Journal. 2011; 34(1): 23-34.

[25] Baloch ZW, Livolsi VA. Encapsulated follicular variant of papillary thyroid carcinoma with bone metastases. Modern Pathology. 2000;
13(8): 861-865. PMid:10955452. https://doi .org/10.1038/mo dpathol. 3880153

[26] Liu C, Chen T, Liu Z. Associations between BRAF(V600E) and prognostic factors and poor outcomes in papillary thyroid carcinoma: a meta-analysis. World J Surg Oncol. 2016; 14: 241. PMid:27600854. https : //doi.org/10.1186/s12957-016-0979-1

[27] Yin DT, Yu K, Lu RQ, et al. Clinicopathological significance of TERT promoter mutation in papillary thyroid carcinomas: a systematic review and meta-analysis.Clin Endocrinol. 2016; 85: 299-305. PMid:26732020. https://doi .org/10.1111/cen. 13017

[28] Luis FK, Art S, Adedayo AO, et al. Differentiated Thyroid Cancer: Millions Spent With No Tangible Gain? Endocr Relat Cancer. 2018; 25(1): 51-57. PMid:29042396. https://doi.org/10.1530/ER C-17-0397

[29] Sabrina J, Jean-Luc B, Drahomir A, et al. and Nicer working group.Overdiagnosis and overtreatment of thyroid cancer: A population-based temporal trend study. PLoS One. 2017; 12(6) PMid:28614405. https://doi.org/10.1371/journal.pone.0 179387

[30] Yang J, Ma Y, Gong Y, et al. Multiple Simultaneous Rare Distant Metastases as the Initial Presentation of Papillary Thyroid Carcinoma: A Case Report. Front Endocrinol (Lausanne). 2019; 10: 759 PMid:31781034. https://doi.org/10.3389/fendo.2019.007 59 